\title{
Short communication: Genetic correlation of bovine leukosis incidence with somatic cell score and milk yield in a US Holstein population
}

\author{
E. A. Abdalla, ${ }^{*} \dagger^{1}$ K. A. Weigel, $\ddagger$ T. M. Byrem, $\S$ and G. J. M. Rosa $\#$ \\ *Department of Animal Sciences, University of Wisconsin, Madison 53706 \\ †Department of Animal Science, University of Benghazi, Benghazi, Libya 21861 \\ ‡Department of Dairy Science, University of Wisconsin, Madison 53706 \\ $\S$ Antel BioSystems Inc., Lansing, MI 48910 \\ \#Department of Biostatistics and Medical Informatics, University of Wisconsin, Madison 53706
}

\begin{abstract}
Bovine leukosis (BL) is a retroviral disease caused by the bovine leukosis virus (BLV), which affects only cattle. Dairy cows positive for BL produce less milk and have more days open than cows negative for BL. In addition, the virus also affects the immune system and causes weaker response to vaccines. Heritability estimates of BL incidence have been reported for Jersey and Holstein populations at about 0.08, indicating an important genetic component that can potentially be exploited to reduce the prevalence of the disease. However, before BL is used in selection programs, it is important to study its genetic associations with other economically important traits such that correlated responses to selection can be predicted. Hence, this study aimed to estimate the genetic correlations of $\mathrm{BL}$ with milk yield (MY) and with somatic cell score (SCS). Data of a commercial assay (ELISA) used to detect BLV antibodies in milk samples were obtained from Antel BioSystems (Lansing, MI). The data included continuous milk ELISA scores and binary milk ELISA results for 11,554 cows from 112 dairy herds across 16 US states. Continuous and binary milk ELISA were analyzed with linear and threshold models, respectively, together with MY and SCS using multitrait animal models. Genetic correlations (posterior means \pm standard deviations) between BL incidence and $\mathrm{MY}$ were $0.17 \pm 0.077$ and $0.14 \pm 0.076$ using ELISA scores and results, respectively; with SCS, such estimates were $0.20 \pm 0.081$ and $0.17 \pm 0.079$, respectively. In summary, the results indicate that selection for higher MY may lead to increased BLV prevalence in dairy herds, but that the inclusion of BL (or SCS as an indicator trait) in selection indexes may help attenuate this problem.
\end{abstract}

Received May 19, 2015.

Accepted November 11, 2015.

${ }^{1}$ Corresponding author: alamroony@gmail.com
Key words: bovine leukosis, genetic correlation, milk yield, somatic cell score

\section{Short Communication}

Bovine leukosis (BL) is a naturally occurring retrovirus disease of cattle caused by the bovine leukosis virus (BLV). It is a transmissible disease that is considered to be of economic importance in the international trade of animals and animal products. The National Animal Health Monitoring System reported widespread BLV in US dairy cattle (NAHMS, 1997, 2007). In fact, the adoption of herd management strategies specific for controlling BLV has been poor and ineffective in reducing the spread of the disease (NAHMS, 2007; Erskine et al., 2012b; Bartlett et al., 2014). In addition, most animals infected with BL do not show any clinical signs of the disease (Schwartz and Levy, 1994), making it even more difficult to prioritize the disease. Moreover, to date, no vaccine is available for the virus.

In a US study to assess the influence of $\mathrm{BL}$ on the immune system and its possible consequences on other disease infections, Erskine et al. (2011) reported that infected animals had impaired responses to J5 Escherichia coli bacterin. Similar reports from other countries (e.g., Yamamoto et al., 1984) showed a considerable worldwide effect of BL. A BLV infection may not affect overall animal health, but it significantly affects the milk yield (MY) at a cellular level (Motton, 2002).

According to Ott et al. (2003), BL economically affects producers and consumers. Those authors indicated that BL was associated with production losses of $\$ 285$ million for producers, which increases the cost of dairy products for consumers. In addition, Thurmond (1987) estimated the nonmilk economic losses at $\$ 80$ million. Many other studies have also demonstrated the economic effect of BL in dairy herds, including decreased MY and reproduction efficiency, and increased mortality rates, cost of replacement, labor, and veterinary service. For example, Brenner et al. (1989) found 
that, on average, a negative BLV cow produces more milk $(3.5 \%)$ and has a longer life span and fewer days open per lactation. The estimated average superiority of negative BLV cows over those positive were $488 \mathrm{~kg}$ of milk, $15 \mathrm{~kg}$ of fat, and $16 \mathrm{~kg}$ of protein per lactation (Byrem et al., 2011). The disease has been reported as the cause for reduced milk yield by 3 (Ott et al., 2003) and 2.5\% (Emanuelson et al., 1992), and this loss may reach up to $5.7 \%$ if a herd completely free of BLV is compared with a completely infected herd (Ott et al., 2003). Also, BL has important effects on the international animal industry and animal products for its effect on reproduction (Vanleeuwen et al., 2010). Recently, Erskine et al. (2012a) reported that decreased herd milk production and cow longevity were associated with increased prevalence of BLV.

Breeding for increased milk production, which has occurred extensively in the last decades, has led to increased susceptibility of dairy cattle to diseases and has also affected fertility traits negatively (Pryce et al., 1997; Rauw et al., 1998; Sandoe et al., 1999). It is well known that genetic selection toward improved milk production reduces the genetic merit for health in dairy cattle populations (Pryce et al., 1997; Windig et al., 2006). To address the decline in reproduction traits and disease resistance, new nutritional and breeding strategies have been suggested to increase milk production while improving the resistance to diseases (Esslemont, 2003; Pryce et al., 2004). Although increased disease incidence in dairy cattle is certainly associated with management and environmental factors, genetics also play a central role. Indirect selection and correlated responses are important when improving genetic merit for milk traits in dairy cattle (Pantelic et al., 2011).

In fact, continued decline in genetic merit for health and reproduction traits has prompted dairy cattle breeding programs to include many nonproduction traits in selection indexes (Pryce et al., 2004). For example, simultaneous selection for improved MY, health, and fertility in Norwegian Red cattle has led to reduction in the probability of culling in first lactation by $0.2 \%$ per year in recent decades (Holtsmark et al., 2008). In this context, the heritability of BL incidence in Jersey and Holstein populations has been estimated at about 0.08 (Abdalla et al., 2013), which reflects an important genetic contribution to BL incidence and can be used to reduce the disease prevalence. However, before BL incidence can be included in selection programs, it is important to understand how it relates to other economically important dairy traits (Philipsson et al., 1995; Heringstad et al., 2000). Hence, the objective of our study was to estimate the genetic correlations of BL with SCS and MY in a Holstein dairy cattle population in the United States using multitrait linear and threshold models for ELISA scores and ELISA results, respectively.

The data used for our study were obtained from milk ELISA test records at Antel BioSystems laboratory (Lansing, MI), which included ELISA scores (continuous values), ELISA results (binary variable; positive or negative), and age of cows at test. The ELISA results were obtained by using the recommended threshold of milk ELISA test (Erskine et al., 2012c); hence, cows that had milk ELISA scores above 0.1 were considered as infected with the disease. In addition, first lactation MY, SCS, and birth year were obtained from the USDA-Agricultural Research Service Animal Improvement Programs Laboratory (Beltsville, MD) records, together with pedigree information. Data used for analyses were limited to animals born between 1994 and 2008, with age at test between 23 and 119 mo, and from herds with at least 10 cows tested. The final data set included then 11,554 daughters of 3,002 Holstein dairy cattle sires (Table 1). More details about the data set and a description of the continuous and binary ELISA variables can be found in Abdalla et al. (2013).

Table 1. Summary statistics of the final data set used for bovine leukosis (BL) genetic analyses

\begin{tabular}{lc}
\hline Item & Measurement \\
\hline Cows with records, no. & 11,554 \\
Sires, no. & 3,002 \\
Daughters per sire, average no. & 3.84 \\
Animals in the pedigree, no. & 20,918 \\
Herds, no. & 112 \\
Birth year (minimum to maximum) & $1994-2008$ \\
Year-season-month of calving, no. & 3,377 \\
Age at test, mo (minimum to maximum) & $23-119$ \\
Milk ELISA score (mean \pm SD) & $0.23 \pm 0.39$ \\
BL frequency, $\%$ [mean (minimum to maximum)] & $37.9(0.8-78.3)$ \\
First lactation MY, ${ }^{2}$ kg (mean \pm SD) & $12,374 \pm 2,079$ \\
SCS (mean \pm SD) & $2.41 \pm 1.41$ \\
\hline${ }^{1}$ BL frequency (\%) across herds. & \\
${ }^{2}$ Milk yield in first lactation. &
\end{tabular}


The data were analyzed using a multitrait animal model approach. Multitrait techniques have some conceptual and practical advantages, such as improving convergence of binary trait analyses, potentially sharpening estimates of genetic parameters, and allowing the estimation of genetic and environmental correlations among traits. In our study, MY, SCS, and ELISA scores, which were all on a continuous scale, were analyzed using a linear model. Alternatively, a threshold model was used to analyze ELISA results (binary) with the other 2 traits. Fixed effects in the model used to analyze ELISA scores (continuous) and results (binary) were age of animal at test, year of birth, and herd effects, all included as factors in the models (i.e., categories). For SCS and MY, the fixed effects included age at calving and the contemporary group of year of calving, month of calving, and herd effects. Besides the residual component, the additive animal effect was the only random effect included in all models. As some preliminary analyses, contemporary groups were used as both fixed and random effects in the models; no important differences were observed in the results.

Milk ELISA scores were analyzed using a linear mixed model, which can be represented in matrix notation as follows:

$$
\left[\begin{array}{l}
\mathbf{y}_{1} \\
\mathbf{y}_{2} \\
\mathbf{y}_{3}
\end{array}\right]=\left[\begin{array}{ccc}
\mathbf{X}_{1} & \mathbf{0} & \mathbf{0} \\
\mathbf{0} & \mathbf{X}_{2} & \mathbf{0} \\
\mathbf{0} & \mathbf{0} & \mathbf{X}_{3}
\end{array}\right]\left[\begin{array}{l}
\boldsymbol{\beta}_{1} \\
\boldsymbol{\beta}_{2} \\
\boldsymbol{\beta}_{3}
\end{array}\right]+\left[\begin{array}{lll}
\mathbf{z} & \mathbf{0} & \mathbf{0} \\
\mathbf{0} & \mathbf{Z} & \mathbf{0} \\
\mathbf{0} & \mathbf{0} & \mathbf{Z}
\end{array}\right]\left[\begin{array}{l}
\mathbf{u}_{1} \\
\mathbf{u}_{2} \\
\mathbf{u}_{3}
\end{array}\right]+\left[\begin{array}{l}
\mathbf{e}_{1} \\
\mathbf{e}_{2} \\
\mathbf{e}_{3}
\end{array}\right],
$$

where $\mathbf{y}_{1}, \mathbf{y}_{2}$, and $\mathbf{y}_{3}$ are vectors of observations of MY, SCS, and milk ELISA scores, respectively; $\boldsymbol{\beta}_{1}$ and $\boldsymbol{\beta}_{2}$ are vectors with the fixed effects of age at calving and contemporary group affecting MY and SCS, and $\boldsymbol{\beta}_{3}$ is a vector with the fixed effects of herd, age at test, and year of birth affecting ELISA scores; $\mathbf{u}_{1}, \mathbf{u}_{2}$, and $\mathbf{u}_{3}$ are vectors of animal direct genetic effects, assumed $\mathbf{u}=\left[\begin{array}{lll}\mathbf{u}_{1}^{\prime} & \mathbf{u}_{2}^{\prime} & \mathbf{u}_{3}^{\prime}\end{array}\right]^{\prime} \sim N(\mathbf{0}, \mathbf{G} \otimes \mathbf{A})$, where $\mathbf{A}$ is the numerator relationship matrix and $\mathbf{G}$ is the additive genetic variance-covariance matrix; $\mathbf{e}_{1}, \mathbf{e}_{2}$, and $\mathbf{e}_{3}$ are vectors of residual effects, assumed $\mathbf{e}=\left[\begin{array}{lll}\mathbf{e}_{1}^{\prime} & \mathbf{e}_{2}^{\prime} & \mathbf{e}_{3}^{\prime}\end{array}\right]^{\prime} \sim N(\mathbf{0}, \mathbf{E} \otimes \mathbf{I})$, where $\mathbf{E}$ is the residual variance-covariance matrix and $\mathbf{I}$ is an identity matrix of appropriate order; and $\mathbf{X}_{1}$, $\mathbf{X}_{2}, \mathbf{X}_{3}$, and $\mathbf{Z}$ are incidence matrices that link observations to their respective fixed and random effects.

The same linear model described above for ELISA scores was also used to analyze the binary ELISA results on its liability scale as follows:

$$
\left[\begin{array}{c}
\mathbf{y}_{1} \\
\mathbf{y}_{2} \\
\lambda
\end{array}\right]=\left[\begin{array}{ccc}
\mathbf{X}_{1} & \mathbf{0} & \mathbf{0} \\
\mathbf{0} & \mathbf{X}_{2} & \mathbf{0} \\
\mathbf{0} & \mathbf{0} & \mathbf{X}_{3}
\end{array}\right]\left[\begin{array}{l}
\boldsymbol{\beta}_{1} \\
\boldsymbol{\beta}_{2} \\
\boldsymbol{\beta}_{3}
\end{array}\right]+\left[\begin{array}{lll}
\mathbf{Z} & \mathbf{0} & \mathbf{0} \\
\mathbf{0} & \mathbf{Z} & \mathbf{0} \\
\mathbf{0} & \mathbf{0} & \mathbf{Z}
\end{array}\right]\left[\begin{array}{l}
\mathbf{u}_{1} \\
\mathbf{u}_{2} \\
\mathbf{u}_{3}
\end{array}\right]+\left[\begin{array}{l}
\mathbf{e}_{1} \\
\mathbf{e}_{2} \\
\mathbf{e}_{3}
\end{array}\right],
$$

where $\boldsymbol{\lambda}$ is a vector of unobserved liabilities and other effects are as described above. The models were implemented using a Bayesian approach with vague conjugate priors (Sorensen and Gianola, 2002). The joint posterior distribution for each model was approximated using a Markov chain Monte Carlo method based on Gibbs sampling using the THRGIBBS1F90 software (Misztal et al., 2002). A single Markov chain Monte Carlo chain with 1,100,000 iterations was run for each model. The first 100,000 samples were discarded as burn-in for convergence, and the remaining samples were thinned with intervals of 100 samples and used to calculate posterior features of interest such as posterior means and standard deviations.

Estimated heritabilities, as well as genetic and residual variances, covariances, and correlations among ELISA score and MY and SCS using the linear model are presented in Tables 2 and 3. Very similar results were found using the threshold analysis of ELISA results (Tables 4 and 5). In both models, BL heritability estimates were similar to those obtained by Abdalla et al. (2013) using single-trait linear and threshold models. Estimates of genetic correlations (posterior mean \pm posterior standard deviation) between BL and $\mathrm{MY}$ were $0.17 \pm 0.077$ and $0.14 \pm 0.076$ using ELISA scores and ELISA results, respectively. Genetic correlations between BL incidence and SCS were also positive and

Table 2. Posterior means \pm posterior standard deviations of genetic variances (on the diagonal), heritabilities (within parentheses), genetic covariances (above the diagonal), and genetic correlations (below the diagonal) for milk yield (MY; in $\mathrm{kg}$ ), SCS, and ELISA scores

\begin{tabular}{lccc}
\hline Item & MY & SCS & ELISA $^{1}$ \\
\hline MY & $887,709 \pm 350,112$ & $209 \pm 46$ & $40 \pm 25$ \\
& $(0.31 \pm 0.086)$ & & $0.034 \pm 0.015$ \\
SCS & $0.33 \pm 0.083$ & $(0.25 \pm 0.097)$ & $0.059 \pm 0.007$ \\
ELISA $^{1}$ & $0.17 \pm 0.079$ & $0.20 \pm 0.081$ & $(0.084 \pm 0.017)$ \\
\hline
\end{tabular}

${ }^{1}$ ELISA $=$ milk ELISA for bovine leukosis test in continuous scale. 
Table 3. Posterior means \pm posterior standard deviations of residual variances (on the diagonal), covariances (above the diagonal), and correlations (below the diagonal) for milk yield (MY; in kg), SCS, and ELISA scores

\begin{tabular}{lccc}
\hline Item & MY & SCS & ELISA $^{1}$ \\
\hline MY & $1,937,848 \pm 142,306$ & $-315 \pm 43$ & $-20 \pm 11$ \\
SCS & $-0.192 \pm 0.026$ & $1.36 \pm 0.05$ & $0.00014 \pm 0.00011$ \\
ELISA $^{1}$ & $-0.019 \pm 0.009$ & $0.00015 \pm 0.0001$ & $0.64 \pm 0.017$ \\
\hline
\end{tabular}

${ }^{1}$ ELISA $=$ milk ELISA for bovine leukosis test in continuous scale.

Table 4. Posterior means \pm posterior standard deviations of genetic variances (on the diagonal), heritabilities (within parentheses), genetic covariances (above the diagonal), and genetic correlations (below the diagonal) for milk yield (MY; in $\mathrm{kg}$ ), SCS, and ELISA results

\begin{tabular}{lccc}
\hline Item & MY & SCS & ELISA $^{1}$ \\
\hline MY & $888,543 \pm 157,120$ & $205 \pm 44$ & $40 \pm 27$ \\
& $(0.31 \pm 0.088)$ & $0.46 \pm 0.55$ & $0.033 \pm 0.016$ \\
SCS & $0.32 \pm 0.084$ & $(0.25 \pm 0.098)$ & $0.088 \pm 0.012$ \\
& & $0.17 \pm 0.077$ & $(0.080 \pm 0.018)$ \\
\hline
\end{tabular}

${ }^{1} \mathrm{ELISA}=$ milk ELISA for bovine leukosis test in binary scale.

Table 5. Posterior means \pm posterior standard deviations of residual variances (on the diagonal), covariances (above the diagonal), and correlations (below the diagonal) for milk yield (MY; in kg), SCS, and ELISA results

\begin{tabular}{lccc}
\hline Item & MY & SCS & ELISA $^{1}$ \\
\hline MY & $1,941,202 \pm 142,419$ & $-311 \pm 42$ & $-21 \pm 12$ \\
SCS & $-0.192 \pm 0.027$ & $1.36 \pm 0.05$ & $0.00014 \pm 0.00011$ \\
ELISA $^{1}$ & $-0.015 \pm 0.009$ & $0.00012 \pm 0.0001$ & $1.0 \pm 0.012$ \\
\hline
\end{tabular}

${ }^{1} \mathrm{ELISA}=$ milk ELISA for bovine leukosis test in binary scale.

the estimates obtained from the 2 ELISA variables were $0.20 \pm 0.081$ and $0.17 \pm 0.079$, respectively. Despite a slight difference between the 2 models in their estimates of genetic correlations, results indicate a modest but unfavorable positive genetic correlation between MY and BL incidence, meaning that selection for increased MY may also increase the liability to BL. In this context, successful selection for higher yields might be one of the reasons for increased BLV infection rates in US dairies (Pryce et al., 2004). Conversely, the genetic correlation between $\mathrm{BL}$ and SCS was also positive, indicating that current selection for lower SCS as an attempt to decrease mastitis incidence in dairy cattle may also help decrease BL prevalence. Additional research on the causes of such a positive correlation would be desirable, for example for the detection of genes that enhance overall animal health and, thus, decrease both BL susceptibility and mastitis incidence. Such an investigation could be performed in the context of genome-wide association analysis with multiple traits using, for example, structural equation modeling approaches (e.g., Rosa et al., 2011).

In summary, the results in terms of genetic variances, heritabilities, and genetic correlations suggest that ge- netic selection could indeed be used to decrease the incidence of BL in US dairies. Such genetic selection could be implemented by including a BL component directly into selection indexes or, alternatively, selecting indirectly for BL through SCS (Philipsson et al., 1995; Heringstad et al., 2000). The relative efficiency of direct and indirect selection for BL incidence, however, will depend not only on the value of genetic parameters, but also on the disease prevalence and selection rate (Foulley, 1992). Lastly, as field data are always prone to biases and confounding due to, for example, nonrandom sampling and preferential treatment, results from their analysis should be interpreted with care. The estimates presented here should be taken as a first attempt to assess the magnitude of genetic parameters associated with BL incidence. Further research on BL incidence in dairy herds, with additional genetic studies and larger data sets, is then necessary.

\section{ACKNOWLEDGMENTS}

This research was partially funded by the Agriculture and Food Research Initiative Competitive Grant no. 
2011-67015-30219 from the USDA National Institute of Food and Agriculture (Washington, DC) to G. Rosa.

\section{REFERENCES}

Abdalla, E. A., G. J. M. Rosa, K. A. Weigel, and T. M. Byrem. 2013. Genetic analysis of leukosis incidence in United States Holstein and Jersey populations. J. Dairy Sci. 96:6022-6029.

Bartlett, P. C., L. M. Sordillo, T. M. Byrem, B. Norby, D. L. Grooms, C. L. Swenson, J. Zalucha, and R. J. Erskine. 2014. Options for the control of bovine leukemia virus in dairy cattle. J. Am. Vet. Med. Assoc. 244:914-922.

Brenner, J., M. Vanhaam, D. Savir, and Z. Trainin. 1989. The implication of BLV infection in the productivity, reproductive capacity and survival rate of a dairy-cow. Vet. Immunol. Immunopathol. $22: 299-305$.

Byrem, T. M., R. J. Erskine, P. C. Bartlett, C. Febvay, C. Render, H. D. Norman, and J. R. Wright. 2011. Prevalence, transmission and impact of bovine leukosis in Michigan dairies. J. Dairy Sci. 94(ESuppl. 1):15. (Abstr.).

Emanuelson, U., K. Scherling, and H. Pettersson. 1992. Relationships between herd bovine leukemia-virus infection status and reproduction, disease incidence, and productivity in Swedish dairy herds. Prev. Vet. Med. 12:121-131.

Erskine, R. J., P. C. Bartlett, T. M. Byrem, C. L. Render, C. Febvay, and J. T. Houseman. 2012a. Association between bovine leukemia virus, production, and population age in Michigan dairy herds. J. Dairy Sci. 95:727-734.

Erskine, R. J., P. C. Bartlett, T. M. Byrem, C. L. Render, C. Febvay, and J. T. Houseman. 2012b. Herd-level determinants of bovine leukaemia virus prevalence in dairy farms. J. Dairy Res. 79:445-450.

Erskine, R. J., P. C. Bartlett, T. M. Byrem, C. L. Render, C. Febvay, and J. T. Houseman. 2012c. Using a herd profile to determine age-specific prevalence of bovine leukemia virus in Michigan dairy herds. Vet. Med. Int. 2012:350374. http://dx.doi. org $/ 10.1155 / 2012 / 350374$.

Erskine, R. J., P. C. Bartlett, K. M. Sabo, and L. M. Sordillo. 2011. Bovine leukemia virus infection in dairy cattle: Effect on serological response to immunization against j5 Escherichia coli bacterin. Vet. Med. Int. 2011:915747.

Esslemont, R. 2003. The costs of poor fertility and what to do about reducing them. Cattle Pract. 11:237-250.

Foulley, J. L. 1992. Prediction of selection response for threshold dichotomous traits. Genetics 132:1187-1194.

Heringstad, B., G. Klemetsdal, and J. Ruane. 2000. Selection for mastitis resistance in dairy cattle: a review with focus on the situation in the Nordic countries. Livest. Prod. Sci. 64:95-106.

Holtsmark, M., B. Heringstad, P. Madsen, and J. Ødegård. 2008. Genetic relationship between culling, milk production, fertility, and health traits in Norwegian Red cows. J. Dairy Sci. 91:4006-4012.

Misztal, I., S. Tsuruta, T. Strabel, B. Auvray, T. Druet, and D. H. Lee. 2002. BLUPF90 and related programs (BGF90). Pages 1-2 in Proc. 7th World Congr. Genet. Appl. Livest. Prod., Montpellier, France, August, 2002. Session 28. Institut National de la Recherche Agronomique (INRA), Paris, France.
Motton, D. D. 2002. Bovine leukosis virus alters growth properties and casein synthesis in mammary epithelial cells. PhD. University of California, Berkeley.

NAHMS. 1997. High Prevalence of BLV in U.S. Dairy Herds. USDA, Animal and Plant Health Inspection Service, Veterinary Service, Center for Epidemiology and Animal Health, National Animal Health Monitoring System, Fort Collins, CO.

NAHMS. 2007. Bovine Leukosis Virus (BLV) on U.S. Dairy Operations. USDA, Animal and Plant Health Inspection Service, Veterinary Services, Center for Epidemiology and Animal Health, National Animal Health Monitoring System, Fort Collins, CO.

Ott, S. L., R. Johnson, and S. J. Wells. 2003. Association between bovine-leukosis virus seroprevalence and herd-level productivity on US dairy farms. Prev. Vet. Med. 61:249-262.

Pantelic, V., L. Sretenovic, D. Ostojic-Andric, S. Trivunovic, M. M. Petrovic, S. Aleksic, and D. Ruzic-Muslic. 2011. Heritability and genetic correlation of production and reproduction traits of Simmental cows. Afr. J. Biotechnol. 10:7117-7121.

Philipsson, J., G. Ral, and B. Berglund. 1995. Somatic cell count as a selection criterion for mastitis resistance in dairy cattle. Livest. Prod. Sci. 41:195-200.

Pryce, J., M. Royal, P. Garnsworthy, and I. L. Mao. 2004. Fertility in the high-producing dairy cow. Livest. Prod. Sci. 86:125-135.

Pryce, J. E., R. F. Veerkamp, R. Thompson, W. G. Hill, and G. Simm. 1997. Genetic aspects of common health disorders and measures of fertility in Holstein Friesian dairy cattle. Anim. Sci. 65:353-360.

Rauw, W. M., E. Kanis, E. N. Noordhuizen-Stassen, and F. J. Grommers. 1998. Undesirable side effects of selection for high production efficiency in farm animals: A review. Livest. Prod. Sci. 56:15-33.

Rosa, G. J. M., B. D. Valente, G. De Los Campos, X. L. Wu, D. Gianola, and M. A. Silva. 2011. Inferring causal phenotype networks using structural equation models. Genet. Sel. Evol. 43:6.

Sandoe, P., B. L. Nielsen, L. G. Christensen, and P. Sorensen. 1999 Staying good while playing god-The ethics of breeding farm animals. Anim. Welf. 8:313-328.

Schwartz, I., and D. Levy. 1994. Pathobiology of bovine leukemiavirus. Vet. Res. 25:521-536.

Sorensen, D., and D. Gianola. 2002. Likelihood, Bayesian, and MCMC Methods in Quantitative Genetics. Springer, New York, NY.

Thurmond, M. C. 1987. Economics of enzootic bovine leukosis. Pages 71-84 in Enzootic Bovine Leukosis and Bovine Leukemia Virus. Springer, New York, NY.

Vanleeuwen, J. A., J. P. Haddad, I. R. Dohoo, G. P. Keefe, A. Tiwari, and R. Tremblay. 2010. Associations between reproductive performance and seropositivity for bovine leukemia virus, bovine viraldiarrhea virus, Mycobacterium avium subspecies paratuberculosis, and Neospora caninum in Canadian dairy cows. Prev. Vet. Med. 94:54-64.

Windig, J. J., M. P. L. Calus, B. Beerda, and R. F. Veerkamp. 2006. Genetic correlations between milk production and health and fertility depending on herd environment. J. Dairy Sci. 89:1765-1775.

Yamamoto, S., M. Onuma, H. Kodama, T. Mikami, and H. Izawa. 1984. Suppression of natural cytotoxic activity of lymphocytes from cattle and sheep during the progress of bovine leukosis. Vet. Microbiol. 9:105-111. 